\title{
Vaccine acceptance
}

\section{The UK perspective}

John A Ford ${ }^{1}$, Hamid Mahgoub ${ }^{2}$, and Ananda Giri Shankar ${ }^{2, *}$

${ }^{1}$ Academic Clinical Fellow in Public Health; University of East Anglia; Norwich, Norfolk, UK; ${ }^{2}$ Public Health England; Anglia Health Protection Team, Anglia

\& Essex PHE Centre; Thetford, Norfolk, UK

Keywords: vaccine acceptance, MMR, pertussis, influenza, shingles, rotavirus, UK

*Correspondence to: Ananda Giri Shankar; Email: giri.shankar@phe.gov.uk

Submitted: 08/20/2013

Accepted: 09/07/2013

http://dx.doi.org/10.4161/hv.26411
$\mathrm{T}$ he United Kingdom (UK) has a long history with vaccine acceptability dating back to Edward Jenner's theory of small pox vaccination. More recently, the discredited, Wakefield study published in 1998 continues to cause MMR skepticism. In pregnant women pertussis vaccination has been considerably more successful than influenza vaccination. Influenza vaccine uptake in healthcare workers remains poor. The media, politicians, and health reforms have contributed to the mixed coverage for these vaccines. In this article we examine vaccine acceptability from a UK perspective, and consider the future impact this is likely to have on the introduction of rotavirus and shingles vaccine in the UK in 2013.

\section{Introduction}

The United Kingdom has a long and varied history with vaccine acceptability. It started in Gloucestershire in 1796 when Edward Jenner was ridiculed from public and professionals for inoculating an eight year old boy with cowpox. ${ }^{1}$ Based on this theory of vaccination, small pox would be eradicated two hundred years later.

In 21st century Britain, the interaction between the public, health professionals, and vaccination remains tempestuous. There remains a strong undercurrent of civil liberties, which has been reinforced by the promotion of patient choice in healthcare (exemplified by the primary website for NHS information, NHS choices $^{2}$ ) and fuelled by a hyper-critical media. Successive governments have taken a predominately individualistic perspective on health choices, rather than a collective, societal perspective. Tony Blair's health reforms championed patient choice to bring "more responsive services." This concept has been extended by the current government, evidenced by the formation of a so-called Nudge Unit within the cabinet office. ${ }^{4}$ The context of vaccine acceptability in the UK has acquired a new dimension following the recent healthcare reforms in England and Wales. ${ }^{5}$ This article considers, from a UK perspective, the acceptability of the MMR, influenza, and pertussis vaccines and looks forward to the introduction of the rotavirus and shingles vaccines.

\section{MMR and Controversy}

The now discredited 1998 study suggesting a link between the MMR vaccine with autistic colitis led by Andrew Wakefield ${ }^{6}$ has had a dramatic effect on MMR acceptability in the UK. The effect on vaccine acceptability has been well documented. ${ }^{7}$ MMR coverage has taken over a decade to recover to pre-Wakefield levels. The lowest was in 2004-05 when coverage was less than $80 \%{ }^{8}$ January to March 2013 coverage of primary and booster still remains $88.5 \%$, " less than the $95 \%$ recommended by World Health Organization (WHO).$^{10}$

In recent months the UK has seen a number of measles outbreaks. The highest incidence was in Wales, where from January to June 2013 there were 1217 notifications (number of confirmed cases has not yet been published). ${ }^{11}$ Most cases were 
individuals who had not been vaccinated. The low vaccine coverage in south Wales has been linked to an intense campaign by a local newspaper, the South Wales Evening Post, against the MMR vaccine. ${ }^{12}$

Before 1998 the average incidence of mumps was less than 200 per year. The incidence of mumps in the UK peaked in 2005 with over 43000 cases with a further peak in 2009. ${ }^{13}$

However it would be overly simplistic to solely attribute the increase in measles and mumps to Wakefield. His article was published in a context ripe for vaccine skepticism. Prior to publication coverage was just over $90 \% .{ }^{14}$ The incidence of measles, mumps, and rubella were at an all-time low, meaning that the public did not feel at risk. According to the health belief model of behavior change, individuals must feel susceptible to a health problem to accept vaccination. ${ }^{15}$

The political and media context vastly increased skepticism. Major newspapers ran front page stories supporting the findings of the Wakefield study. The media portrayed Wakefield as a genuine researcher who had boldly decided to whistle-blow. This was juxtaposed to the growing mistrust in the response from the Department of Health and politicians. The Department of Health was issuing reassuring messages to the public about the safety of the vaccine, only for Tony Blair, the then Prime Minister, to refuse to disclose if his son had received the vaccine. ${ }^{16}$

While the majority of UK public now generally accepts that the findings of the Wakefield study are not correct, there remains a sizeable proportion which maintains concerns about the safety of the MMR. These groups generally have entrenched anti-vaccine opinions and cite reasons such as immune overload (too many vaccinations for infants), toxic vaccine ingredients, and doctors operating on target driven financial motives. ${ }^{17}$

\section{Pertussis and Influenza Vaccine in Pregnancy}

In the UK the pertussis vaccine in pregnancy was introduced in October 2012 after an increase in cases of whooping cough. Latest figures suggest that pertussis uptake in pregnancy is almost $60 \%$ (February 2013). ${ }^{18}$ The influenza vaccine was introduced in pregnancy in 2010 following the swine flu pandemic in which pregnant women were more at risk. The influenza vaccine is coverage is only $40 \% .^{19}$

There are two main reasons for the difference in coverage between influenza and pertussis. First the pertussis vaccine is administered to protect the unborn child, rather than the mother. Mothers are more likely to adopt a health behavior if it improves the health of their unborn child. This is reflected in the number of mothers who give up smoking during pregnancy. The need to protect their own children is a strong driver and it should be recognized that attempts to persuade individuals on the grounds of herd immunity appear to be ineffective; parents make decisions which they feel are best for their family, rather than the wider population. Mothers may also feel pressure to be vaccinated in case they are judged by health professionals or peers. Second it is a common perception that the morbidity and mortality associated with flu is low. The majority of the public believe that at its worst, seasonal flu results in a few days bed rest.

Pertussis vaccine is not licensed for use in pregnancy in the UK and the patient information sheet of $\operatorname{Repevax}^{\odot}$ states that it should not be used in pregnancy. While health professionals understand this is because of a lack of research and not efficacy or safety concerns, it causes mothers considerable anxiety. The UK is becoming increasingly careful about environmental exposures in pregnancy and mothers find it difficult to accept an untested vaccine.

The poor coverage of the flu vaccine in pregnant women is likely to be worsened by the poor uptake among healthcare workers.

\section{Influenza Vaccine in Healthcare Workers}

Influenza vaccine uptake in healthcare workers (HCWs) is surprisingly poor in the UK. Coverage was $46 \%$ in 2012/13. ${ }^{20}$ Vaccination is important to protect patients and reduce sickness absences during an outbreak. Healthcare workers do not appear to be more at risk than other population groups. ${ }^{21}$ According to the health belief model healthcare workers should be some of the most adherent individuals; they know the risks of influenza and understand the importance of vaccination. However, there is limited evidence that vaccinating HCWs reduces flu morbidity and mortality even in high risk groups. ${ }^{22}$ Also, the perceived severity of influenza in healthcare workers may be low because the number of patients who become significantly unwell in hospital is relatively small. Gaps in vaccine uptake research of HCWs include different behavioral patterns and HCWs' own risk acceptability. In the UK doctors and nurses work busy irregular shifts which makes uptake at workplace programs difficult. In addition to ensuring better accessibility and targeted workplace vaccination programs, the low uptake in influenza vaccination among HCWs can be improved by pursuing high quality studies to address current gaps in vaccine uptake research. Healthcare works need to champion immunization in order to improve coverage in the wider population.

\section{Looking to the Future}

The UK will introduce the shingles vaccine for older adults and rotavirus for infants in 2013. ${ }^{23,24}$ Evidence from MMR studies has already shown that a proportion of mothers believe that infants are given too many vaccinations. ${ }^{17}$ The UK has introduced the rotavirus vaccine and this is likely to reinforce these views. However this should not be a reason to prevent infants benefiting from the rotavirus vaccine.

The shingles vaccine will be introduced in older adults in 2013. It may be easier to achieve a higher coverage in older people because they are more likely to have frequent contact with health care, thus providing more opportunities to vaccinate.

The health service in the UK has changed significantly after the NHS reforms with the further expansion of market forces. This has increased the number of private providers who can operate for profit and have contractual obligations to commissioners. Undoubtedly this will lead to further targets with associated financial incentives. This may increase 
the mistrust of the public in vaccination campaigns and be detrimental to public health.

\section{Conclusion}

The UK has had a turbulent relationship with vaccine acceptability, driven primarily by the media, politicians and health reforms. A small but significant, anti-vaccination sentiment remains and we are yet to see how the UK public will respond to the introduction of the rotavirus and shingles vaccines. The Department of Health, commissioners and frontline healthcare staff need to re-build trust if an improvement in vaccine coverage is to be achieved.

\section{Disclosure of Potential Conflicts of Interest}

The views expressed by the authors in this article are purely their own and does not necessarily reflect the views of the organization that they currently work for or have worked for in the past.

\section{References}

1. Riedel S. Edward Jenner and the history of smallpox and vaccination. [Bayl Univ Med Cent]. Proc (Bayl Univ Med Cent) 2005; 18:21-5; PMID:16200144

2. National Health Service. http://www.nhs.uk/. Accessed 6th August 2013.

3. Brown H. Tony Blair's legacy for the UK's National Health Service. Lancet 2007; 369:167982; PMID:17523221; http://dx.doi.org/10.1016/ S0140-6736(07)60763-6

4. United Kingdom Cabinet Office. https://www.gov. uk/government/organisations/behavioural-insightsteam. Accessed 6th August 2013.

5. Department of Health. Equity and Excellence, Liberating the NHS (England). 2010. London. Available at https://www.gov.uk/government/publications/liberating-the-nhs-white-paper. Accessed 6th August 2013.

6. Wakefield AJ, Murch SH, Anthony A, Linnell J, Casson DM, Malik M, Berelowitz M, Dhillon AP, Thomson MA, Harvey P, et al. Ileal-lymphoidnodular hyperplasia, non-specific colitis, and pervasive developmental disorder in children. Lancet 1998; 351:637-41; PMID:9500320; http://dx.doi. org/10.1016/S0140-6736(97)11096-0
7. Casiday R, Cresswell T, Wilson D, Panter-Brick C. A survey of UK parental attitudes to the MMR vaccine and trust in medical authority. Vaccine 2006; 24:17784; PMID:16157422; http://dx.doi.org/10.1016/j. vaccine. 2005.07 .063

8. Health and Social Care Information Centre. NHS Immunisation Statistics, England 2011-12. London, 2012. Available at https://catalogue.ic.nhs.uk/publications/public-health/immunisation/nhs-immu-stateng-2011-2012/nhs-immu-stat-eng-2011-12-rep.pdf. Accessed 6th July 2013.

9. Public Health England. Quarterly vaccination coverage statistics for children aged up to five years in the UK (COVER programme): January to March 2013. London, 2013. Available at http://www.hpa. org.uk/Topics/InfectiousDiseases/InfectionsAZ/ VaccineCoverageAndCOVER/. Accessed 6th August 2013.

10. World Health Organisation. Why immunization must remain a priority in the WHO European Region. Copenhagen 2010. Available at http://www. euro.who.int/__data/assets/pdf_file/0017/84302/ Seven_Key_Reasons.pdf. Accessed 6th August 2013.

11. Public Health Wales. Measles Outbreak: Data. Cardiff, 2013. Available at http://www.wales.nhs.uk/ sitesplus/888/page/66389\#a. Accessed 6th July 2013.

12. Mason BW, Donnelly PD. Impact of a local newspaper campaign on the uptake of the measles mumps and rubella vaccine. J Epidemiol Community Health 2000; 54:473-4; PMID:10818125; http://dx.doi. org/10.1136/jech.54.6.473

13. Public Health England. Confirmed cases of Measles, Mumps and Rubella 1996-2012. London, 2013. Available at http://www.hpa. org.uk/web/HPAweb \& H PAwebStandard/ HPAweb_C/1195733833790. Accessed 6th August 2013.

14. Department of Health. NHS Immunisation Statistics, England: 1997-98. London, 1998. Available at http://webarchive.nationalarchives.gov. uk/20130107105354/http://www.dh.gov.uk/prod_ consum_dh/groups/dh_digitalassets/@dh/@en/ documents/digitalasset/dh_4021496.pdf. Accessed 6th August 2013.

15. Rosenstock IM. The Health Belief Model and Preventive Health Behavior. Health Educ Behav 1974; 2:354-86

16. GuillaumeL, Bath PA. Acontent analysis of mass media sources in relation to the MMR vaccine scare. Health Informatics J 2008; 14:323-34; PMID:19008281; http://dx.doi.org/10.1177/1460458208096654

17. Brown KF, Long SJ, Ramsay M, Hudson MJ, Green J, Vincent CA, Kroll JS, Fraser G, Sevdalis NUK. U.K. parents' decision-making about measles-mumpsrubella (MMR) vaccine 10 years after the MMRautism controversy: a qualitative analysis. Vaccine 2012; 30:1855-64; PMID:22230590; http://dx.doi. org/10.1016/j.vaccine.2011.12.127
18. Department of Health. Pertussis vaccination programme for pregnant women 2012-2013. London, 2013. Available at https://www.gov.uk/government/uploads/system/uploads/attachment_data/ file/191483/PertussisUptake_Feb2013_acc.pdf. Accessed 6th August 2013.

19. Public Health England. Influenza Vaccine Uptake amongst GP Patient Groups in England: Winter Season 2012/13. London, 2013. Available at https:// www.gov.uk/government/uploads/system/uploads/ attachment_data/file/207134/Influenza_vaccine_ uptake_amongst_GP_patient_groups_in_England_ for_winter_season_2012_2013.pdf. Accessed 6th August 2013.

20. Public Health England. Seasonal influenza vaccine uptake amongst frontline healthcare workers (HCWs) in England: Winter season 2012/13. London, 2013. Available at https://www.gov.uk/government/uploads/system/uploads/attachment_data/ file/207556/Seasonal_Influenza_Vaccine Uptake HCWs_2012_13_web.pdf. Accessed 6th August 2013.

21. Williams CJ, Schweiger B, Diner G, Gerlach F, Haaman F, Krause G, Nienhaus A, Buchholz U. Seasonal influenza risk in hospital healthcare workers is more strongly associated with household than occupational exposures: results from a prospective cohort study in Berlin, Germany, 2006/07. BMC Infect Dis 2010; 10:8; PMID:20067628; http://dx.doi. org/10.1186/1471-2334-10-8

22. Thomas RE, Jefferson T, Lasserson TJ. Influenza vaccination for healthcare workers who work with the elderly. Cochrane Database Syst Rev 2010; CD005187; PMID:20166073

23. Public Health England. Rotavirus vaccination programme for infants. London, 2013. Available at https://www.gov.uk/government/organisations/ public-health-england/series/rotavirus-vaccinationprogarmme-for-infants. Accessed 6th July 2013.

24. Public Health England. Shingles vaccination programme. London, 2013. Available at https://www. gov.uk/government/organisations/public-healthengland/series/shingles-vaccination-programme. Accessed 6th July 2013. 